Supporting Information for:

\title{
Insights into multiphase reactions during self-discharge of Li- $S$ batteries
}

Guobin Wen, ${ }^{\mathrm{a},=}$ Sarish Rehman, ${ }^{\mathrm{a}, \mathrm{b},=}$ Tom G. Tranter, ${ }^{\mathrm{a}, \mathrm{c},=}$ Debasis Ghosh, ${ }^{\mathrm{d}}$ Zhongwei Chen, ${ }^{a}$ Jeff T. Gostick, ${ }^{a, *}$ Michael A. Pope ${ }^{a, b, *}$

a Department of Chemical Engineering, University of Waterloo, Waterloo, Ontario N2L 3G1, Canada. ${ }^{\mathrm{b}}$ Quantum Nano Centre, Department of Chemical Engineering, University of Waterloo, Waterloo, Ontario N2L 3G1, Canada.

c Electrochemical Innovation Lab, Department of Chemical Engineering, University College London, Torrington Place, London WC1E 7JE, United Kingdom.

d Centre for Nano \& Material sciences, JAIN University, Jain Global Campus, Bangalore 562112, India.

$=$ These authors contributed equally to this work.

Corresponding Author

* Jeff T. Gostick, Email: jgostick@uwaterloo.ca;

* Michael A. Pope, Email: michael.pope@uwaterloo.ca 
Table of Contents

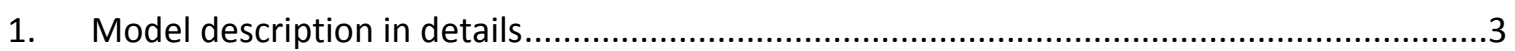

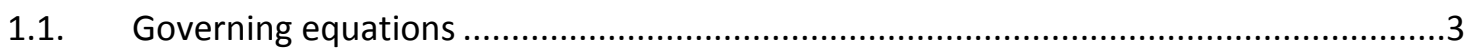

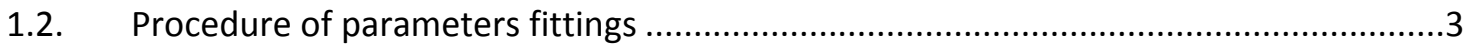

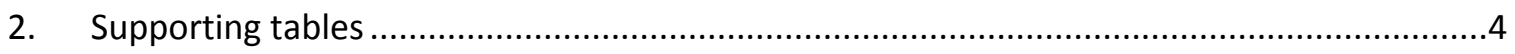

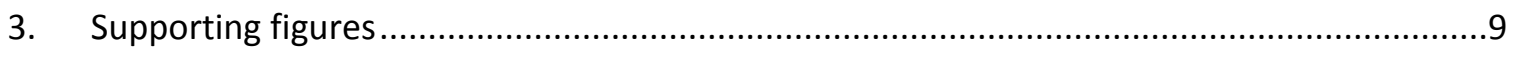




\section{Model description in details}

\subsection{Governing equations}

Bruggeman relation ${ }^{1}$ :

$$
D_{i}=D_{i, 0} \varepsilon^{b}
$$

where $D_{i, 0}$ is the diffusion coefficient in bulk medium, and $\mathrm{b}$ is the Bruggeman coefficient account for the porosity and tortuosity of the porous separator and cathode.

The liquid phase current density is related to the flux of ionic species by:

$$
I_{l}=F \sum_{i} z_{i} N_{i}
$$

where $z_{i}$ is the charge number of species $i$.

The solid phase potential is governed by Ohm's Law:

$$
I_{s}=-\sigma \nabla \varphi_{s}
$$

Current is transferred between liquid and solid via the electrochemical reactions:

$$
\nabla \cdot I_{l}=a \sum_{j} I_{j}
$$

And conservation of charge leads to:

$$
\nabla \cdot I_{l}+\nabla \cdot I_{s}=0
$$

\subsection{Procedure of parameters fittings}

Due to the complexity of the chemistry in this system, we have tried our best to narrow the many parameters used to a reasonable range, using literature sources ${ }^{1-3}$ and our experimental results using the following procedure:

Firstly, the values reported in prior works ${ }^{1-3}$ were used to perform the initial simulations. We then carried out sensitivity analyses on some those parameters which had not been experimentally verified. We then compared the voltage profiles during one charge-discharge cycle of Li-S batteries between simulation and our experiments as shown in Figure $1 \mathrm{~d}$ in the main manuscript. Due to the complexity of Li-S models, we aimed only to depict essential features, such as the two discharging plateaus, and best fit the experimental curves. We hope that in the future, a larger set of experimentally validated parameters will be achieved which we will build into our future work. 


\section{Supporting tables}

Table S1. The stoichiometries for each species

\begin{tabular}{ccccccc}
\hline & \multicolumn{7}{c}{ Reactions $\mathrm{j}$} \\
Species & $\mathrm{A} 1$ & $\mathrm{C} 1$ & $\mathrm{C} 2$ & $\mathrm{C} 3$ & $\mathrm{C} 4$ & $\mathrm{C} 5$ \\
\hline $\mathrm{Li}^{+}$ & -1 & 0 & 0 & 0 & 0 & 0 \\
$\mathrm{~S}_{8}(\mathrm{I})$ & 0 & -0.5 & 0 & 0 & 0 & 0 \\
$\mathrm{~S}_{8}^{2-}$ & 0 & 0.5 & -1.5 & 0 & 0 & 0 \\
$\mathrm{~S}_{6}{ }^{2-}$ & 0 & 0 & 2 & -1 & 0 & 0 \\
$\mathrm{~S}_{4}{ }^{2-}$ & 0 & 0 & 0 & 1.5 & -0.5 & 0 \\
$\mathrm{~S}_{2}^{2-}$ & 0 & 0 & 0 & 0 & 1 & -0.5 \\
$\mathrm{~S}^{2-}$ & 0 & 0 & 0 & 0 & 0 & 1 \\
\hline
\end{tabular}


Table S2. The transport properties and reference concentrations

\begin{tabular}{cccc}
\hline Species, $i$ & $\mathrm{z}_{i}$ & $\mathrm{D}_{i 0}\left[\mathrm{~m}^{2} / \mathrm{s}\right]^{\mathrm{As}}$ & $c_{i, \mathrm{ref}}\left[\mathrm{mol} / \mathrm{m}^{3}\right]^{\mathrm{Se}}$ \\
\hline $\mathrm{Li}^{+}$ & 1 & $1.00 \times 10^{-10}$ & 1001.08 \\
$\mathrm{~S}_{8(1)}$ & 0 & $1.00 \times 10^{-9}$ & 19 \\
$\mathrm{~S}_{8}{ }^{2-}$ & -2 & $6.00 \times 10^{-10}$ & 0.1832 \\
$\mathrm{~S}_{6}{ }^{2-}$ & -2 & $6.00 \times 10^{-10}$ & 0.3351 \\
$\mathrm{~S}_{4}{ }^{2-}$ & -2 & $1.00 \times 10^{-10}$ & 0.0215 \\
$\mathrm{~S}_{2}{ }^{2-}$ & -2 & $1.00 \times 10^{-10}$ & $6.00 \times 10^{-7}$ \\
$\mathrm{~S}^{2-}$ & -2 & $1.00 \times 10^{-10}$ & $9.94 \times 10^{-10}$ \\
\hline
\end{tabular}

As Assumed parameters based on reported literature data.

se Assumed parameters based on reported literature data and sensitivity analyses were performed and discussed in the following session. 
Table S3. Precipitation parameters

\begin{tabular}{cccc}
\hline Precipitate & Rate constant ${ }^{A s}$ & Solubility product As & Molar Volume $\left[\mathrm{m}^{3} / \mathrm{mol}^{\mathrm{As}}\right.$ \\
\hline \multirow{2}{*}{$\mathrm{S}_{8}$} & {$[1 / \mathrm{s}]$} & {$\left[\mathrm{mol} / \mathrm{m}^{3}\right]$} & \\
& 1.0 & 19.0 & $1.24 \times 10^{-4}$ \\
$\mathrm{Li}_{2} \mathrm{~S}_{8}$ & $1.00 \times 10^{-13}$ & $1.83 \times 10^{5}$ & \\
$\mathrm{Li}_{2} \mathrm{~S}_{4}$ & $9.98 \times 10^{-14}$ & $2.14 \times 10^{4}$ & $1.36 \times 10^{-4}$ \\
$\mathrm{Li}_{2} \mathrm{~S}_{2}$ & $9.98 \times 10^{-11}$ & $6.01 \times 10^{2}$ & $7.42 \times 10^{-5}$ \\
$\mathrm{Li}_{2} \mathrm{~S}$ & $6.88 \times 10^{-10}$ & 9950 & $4.32 \times 10^{-5}$ \\
\hline
\end{tabular}

${ }^{\text {As }}$ Assumed parameters based on reported literature data. 
Table S4. Other constant parameters

\begin{tabular}{ccc}
\hline Parameter Names & Values & Description \\
\hline L_pos & $36[\mathrm{um}]^{\text {As }}$ & Cathode electrode thickness \\
L_sep & $25[\mathrm{um}]^{\mathrm{Ex}}$ & Separator thickness \\
T & $303.15[\mathrm{~K}]^{\mathrm{Ex}}$ & Temperature \\
I_ch & $3.55\left[\mathrm{~A} / \mathrm{m}^{2}\right]^{\text {As }}$ & Charge current density \\
I_dch & $-3.55\left[\mathrm{~A} / \mathrm{m}^{2}\right]^{\text {As }}$ & Discharge current density \\
Kappa_C & $100\left[\mathrm{~S} / \mathrm{m}^{\text {As }}\right.$ & Electrode conductivity \\
Kappa_Li & $0.04\left[\mathrm{~S} / \mathrm{m}^{\text {As }}\right.$ & Electrolyte conductivity \\
eps_cat_init & $0.365^{\mathrm{Ex}}$ & Initial total solid volume fraction in cathode \\
eps_cat_S8_init & $0.285^{\text {As }}$ & Initial volume fraction of S in cathode \\
eps_sep_init & $0.550^{\mathrm{Ex}}$ & Initial solid volume fraction in the separator \\
eta_ch $\left(\eta_{\text {ch }}\right)$ & $0.45[\mathrm{~V}]^{\text {As }}$ & Chemical overpotential \\
\hline
\end{tabular}

As Assumed parameters based on reported literature data.

Ex Derived from experimental measurements.

The calculation of specific capacity:

The initial concentration of $\mathrm{S}_{8}$ is about $2200 \mathrm{~mol} / \mathrm{m}^{3}$ from Figure $1 \mathrm{~d}$ using present initial combination of parameters. With the cathode diameter of $10 \mathrm{~mm}$, we can get the sulfur loading is $4.42 \mathrm{mg} / \mathrm{cm}^{2}$ in the simulation model. When the current density was set to $3.55 \mathrm{~A} / \mathrm{m}^{2}$ and discharge time was calculated as 10 hours, the specific capacity can be derived as $630 \mathrm{mAh} / \mathrm{g}$ in simulation model. 
Table S5. Reversible and irreversible capacity losses calculated using the equations (11-14)

\begin{tabular}{cccc}
\hline $\boldsymbol{V}_{\text {rest }}(\mathrm{V})$ & $\boldsymbol{C}_{\mathrm{t}, \mathrm{CL}}(\%)$ & $\boldsymbol{C}_{\text {ir,CL }}(\%)$ & $\boldsymbol{C}_{\text {rev,CL }}(\%)$ \\
\hline $\mathbf{2 . 0 4}$ & 5.24 & 1.87 & 3.37 \\
$\mathbf{2 . 1}$ & 9.67 & 7.1 & 2.57 \\
$\mathbf{2 . 7}$ & 21.1 & 8.4 & 12.7 \\
$\mathbf{2 . 2 5}$ & 9.08 & 1.28 & 7.8 \\
$\mathbf{1 . 9 5}$ & -2.04 & 0.93 & -1.11 \\
\hline
\end{tabular}




\section{Supporting figures}
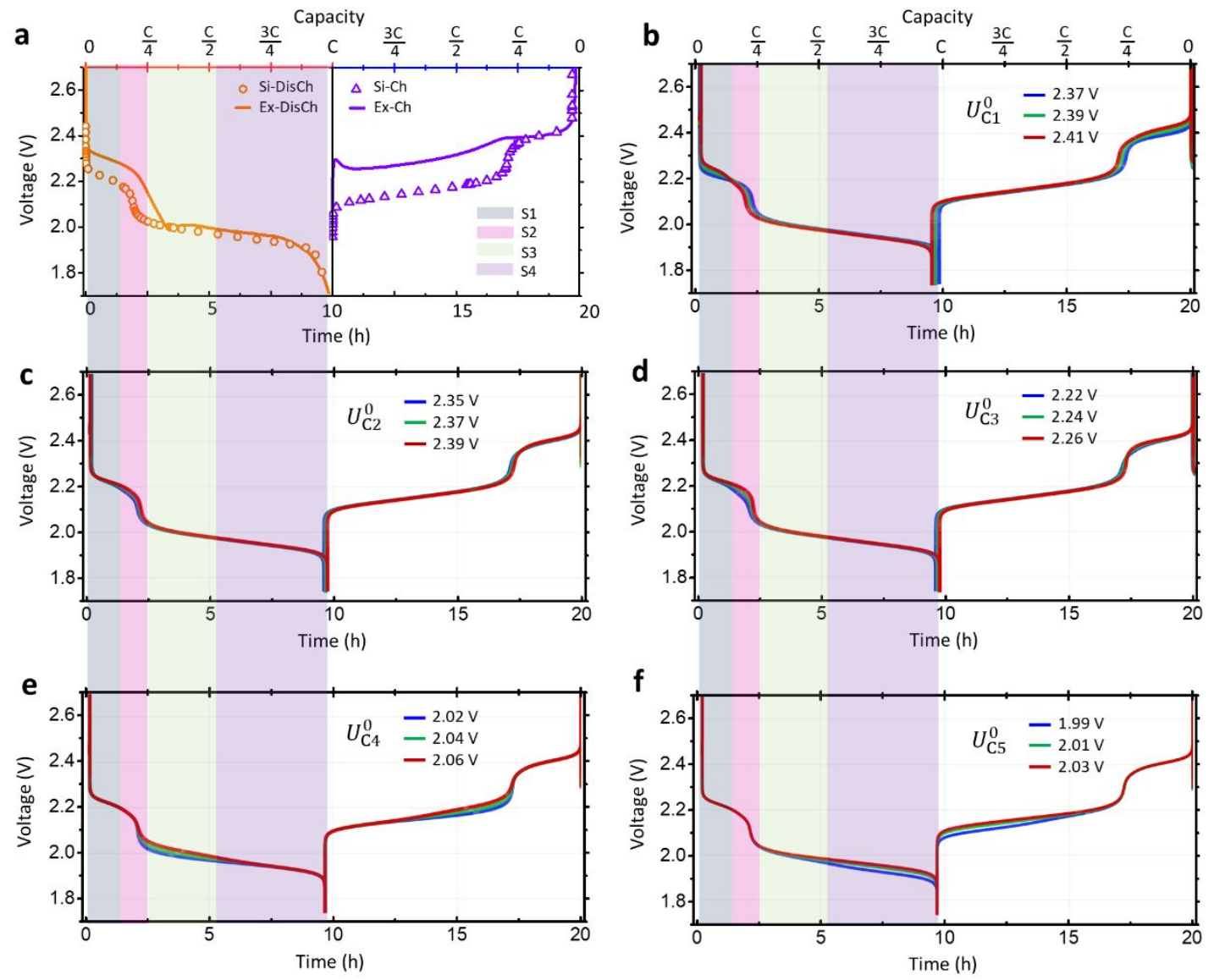

Figure S1. (a) Comparison of experimental (Ex) vs. simulated (Si) voltage profiles during one discharge-charge cycle of Li-S batteries. The same as Figure 1d in the manuscript. (b-f) The sensitivity analyses of the formal potential potentials for electrochemical reactions in the sulfur cathode on voltage profile during a discharge-charge cycle. The discharge profile was divided into four sections: S1-dominated by Reaction C1; S2-dominated by Reaction C2 and C3; S3dominated by Reaction C4; S4-dominated by Reaction C5.

The Reaction A1 was chosen as the reference reaction, so the formal potential $\left(U_{\mathrm{A} 1}^{0}\right)$ was set as zero. There are four sections in the discharging voltage profile, named S1-S4. In S1, the discharging curve is dominated by Reaction $\mathrm{C} 1$. Increasing the formal potential $\left(U_{\mathrm{C} 1}^{0}\right)$ results in increasing of higher voltage plateau and shortening the discharging time due to a faster Reaction $\mathrm{C} 1$. Reaction $\mathrm{C} 2$ and $\mathrm{C} 3$ control S2 region. The larger values of formal potential $\left.\left(U_{\mathrm{C} 2}^{0}, U_{\mathrm{C} 3}^{0}\right)\right)$ lead to a higher voltage plateau and expending of discharging time. Reaction C4 and C5 control discharging in S3 and S4 regions, respectively. Still increasing the formal potentials shift the profile upward. From this analyses, we deemed the values from ref ${ }^{1}$ to be acceptable. 

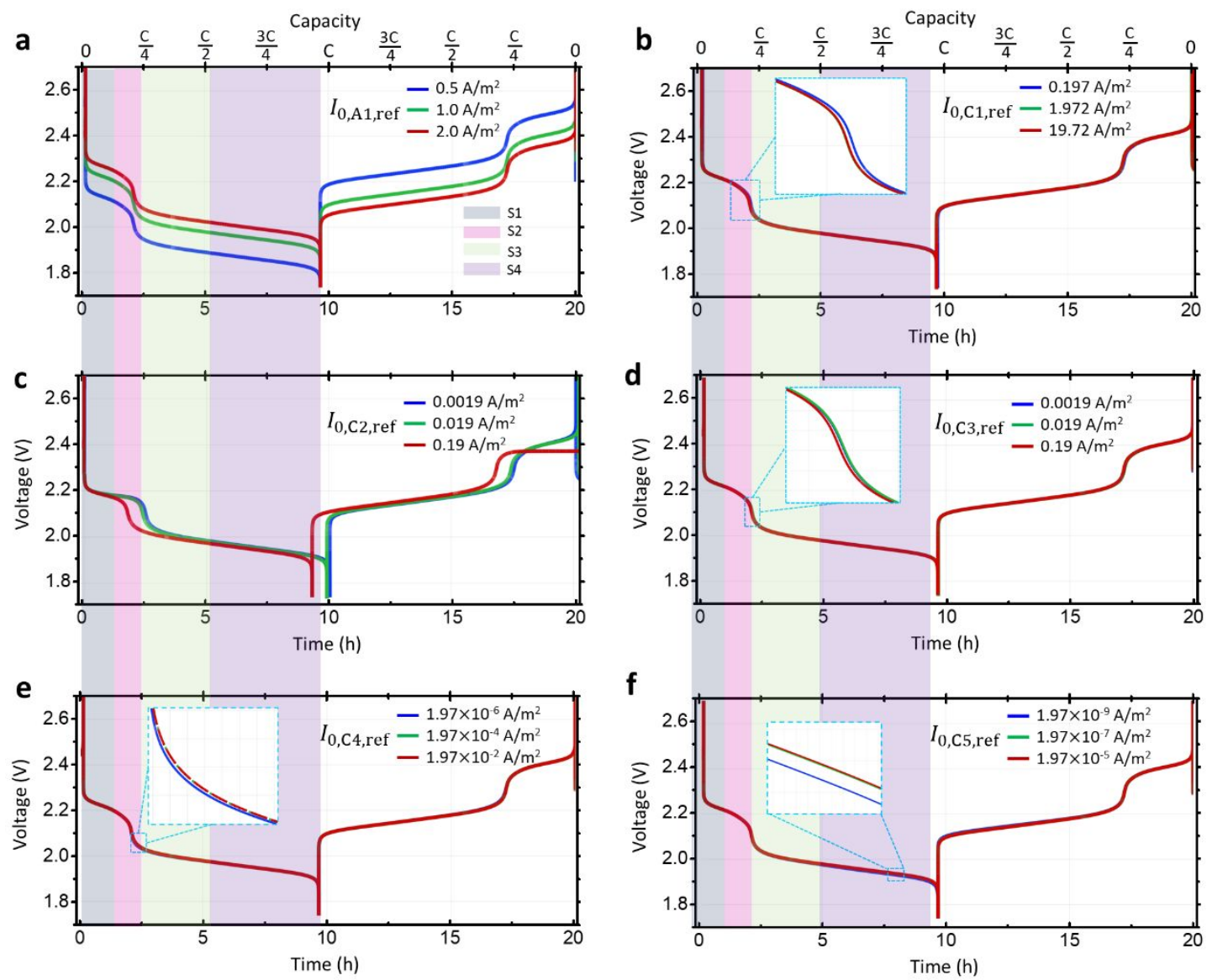

Figure S2. The sensitivity analyses of exchange current densities electrochemical reactions in lithium anode and sulfur cathode on voltage profile during a discharge-charge cycle. The discharge profile was divided into four sections: S1-dominated by Reaction C1; S2-dominated by Reaction C2 and C3; S3-dominated by Reaction C4; S4-dominated by Reaction C5.

The exchange current density variation of Reaction $\mathrm{A} 1\left(i_{0, \mathrm{~A} 1, \mathrm{ref}}\right)$ shift the discharging profile upwards, while the charging profile downwards. The discharging voltage profile is not sensitive on $i_{0, \mathrm{C} 1 \text {,ref }}$ with the change of 10 times, the same as exchange current densities of Reaction C3, C4 and C5 with the variation of 100 times. Regarding Reaction C2, the increasing of $i_{0, \mathrm{C} 2 \text {,ref }}$ speeds up the reaction and shrinks the discharging time. After analyses, we accepted the values from ref ${ }^{1}$

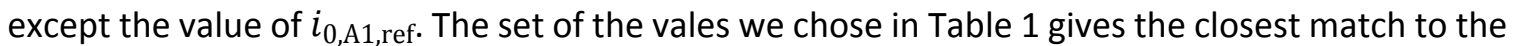
experimental discharging profiles. 

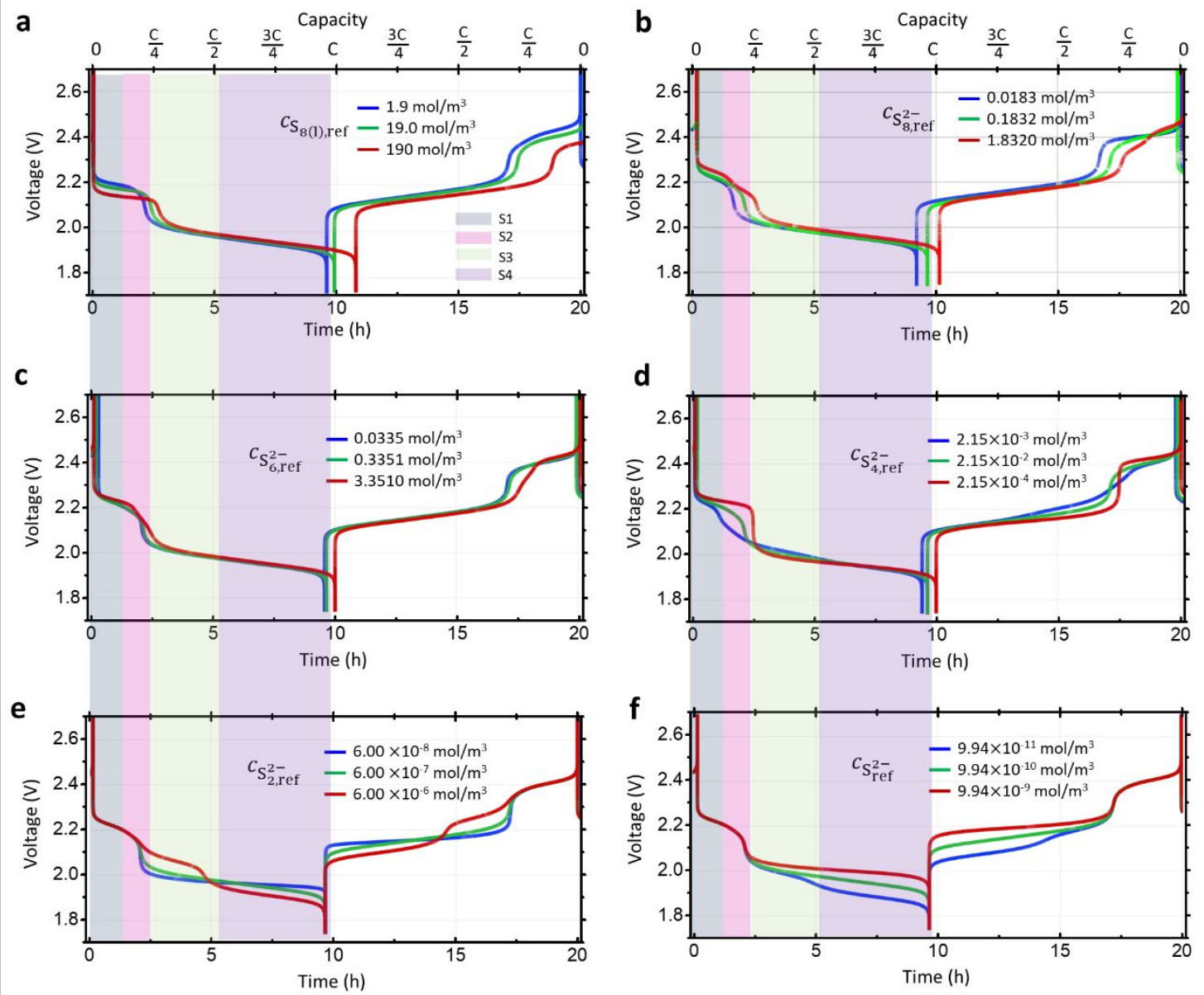

Figure S3. The sensitivity analyses of reference concentration for electrochemical reactions in the sulfur cathode on voltage profile during a discharge-charge cycle. The discharge profile was divided into four sections: S1-dominated by Reaction C1; S2-dominated by Reaction C2 and C3; S3-dominated by Reaction C4; S4-dominated by Reaction C5.

The reference concentrations of different species also plays an important role. Due to the first plateau are dominated by Reaction $C 1$, so the higher value of $c_{S_{8(1), r e f}}$ will reduce the first plateau. Meanwhile, it also increases the discharge time due to the effect on reference potential and current density in Eqn. (1-3). The value of $c_{S_{8,}^{2}, r e f}$ is crucial on the steeply declines between the first and second plateau in the discharge profile. The variation of $c_{S_{6}^{2} \text {, ref }}^{2}$ and $c_{S_{4}^{2} \text {, ref }}^{2}$ further confirm the section S2 was controlled by Reaction C2 and C3. After analyses. While the model might be extended to improve the fit, our model still can reproduce most of behavior of a Li-S cell well. 


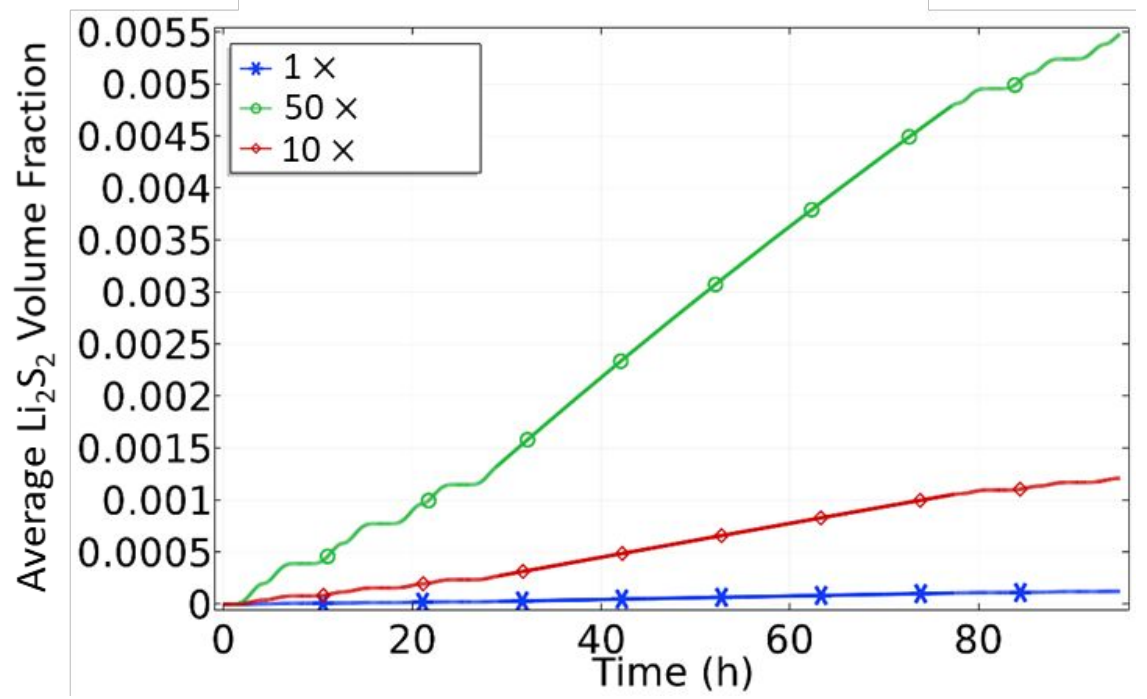

Figure S4. The sensitivity analysis on precipitation reaction rates.

When increasing the precipitation reaction rate, the volume fraction of $\mathrm{Li}_{2} \mathrm{~S}_{2}$ increased rapidly and lead to unphysical behavior. 
$V_{\text {rest }}=2.65 \mathrm{~V}$, $\mathrm{DOD}=0 \%$

$V_{\text {rest }}=2.20 \mathrm{~V}$, $\mathrm{DOD}=16 \%$

$V_{\text {rest }}=2.10 \mathrm{~V}$, $\mathrm{DOD}=25 \%$
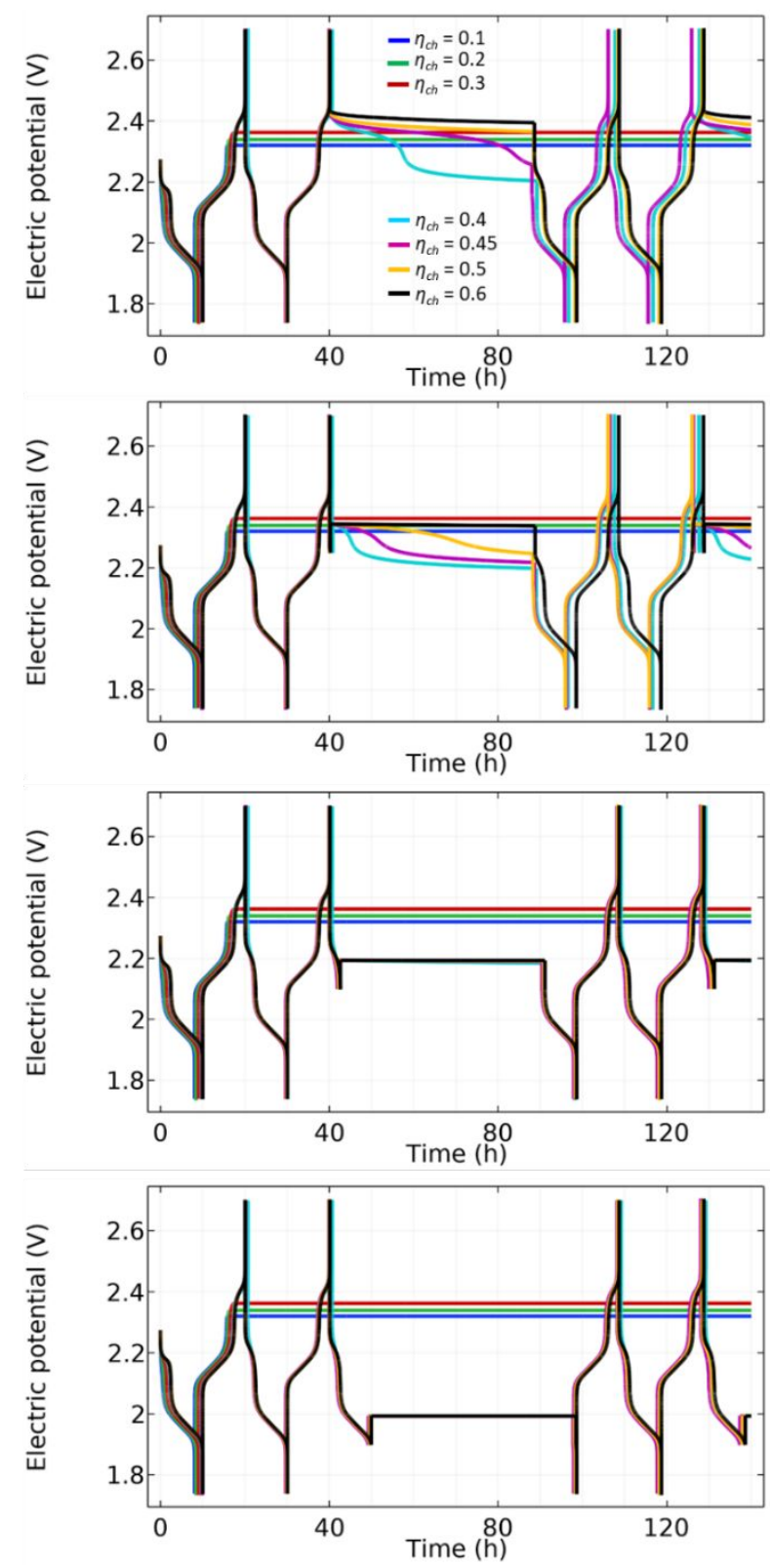

Figure S5. The sensitivity analyses on chemical overpotentials.

The lower values of chemical overpotential mean the chemical reactions at the anode are too fast and lead to infinite charging. This phenomenon occurs during charging if polysulfides are reduced at the negative electrode, where electrons are readily available. The shorter polysulfides migrate back to the positive electrode where they are oxidized again. ${ }^{5}$ The higher values of chemical overpotential mean the rate of reduction is so slow that there is no major effect on the performance. Choosing $0.45 \mathrm{~V}$ in the model led to the simulation most closely approximated the experimental results. 

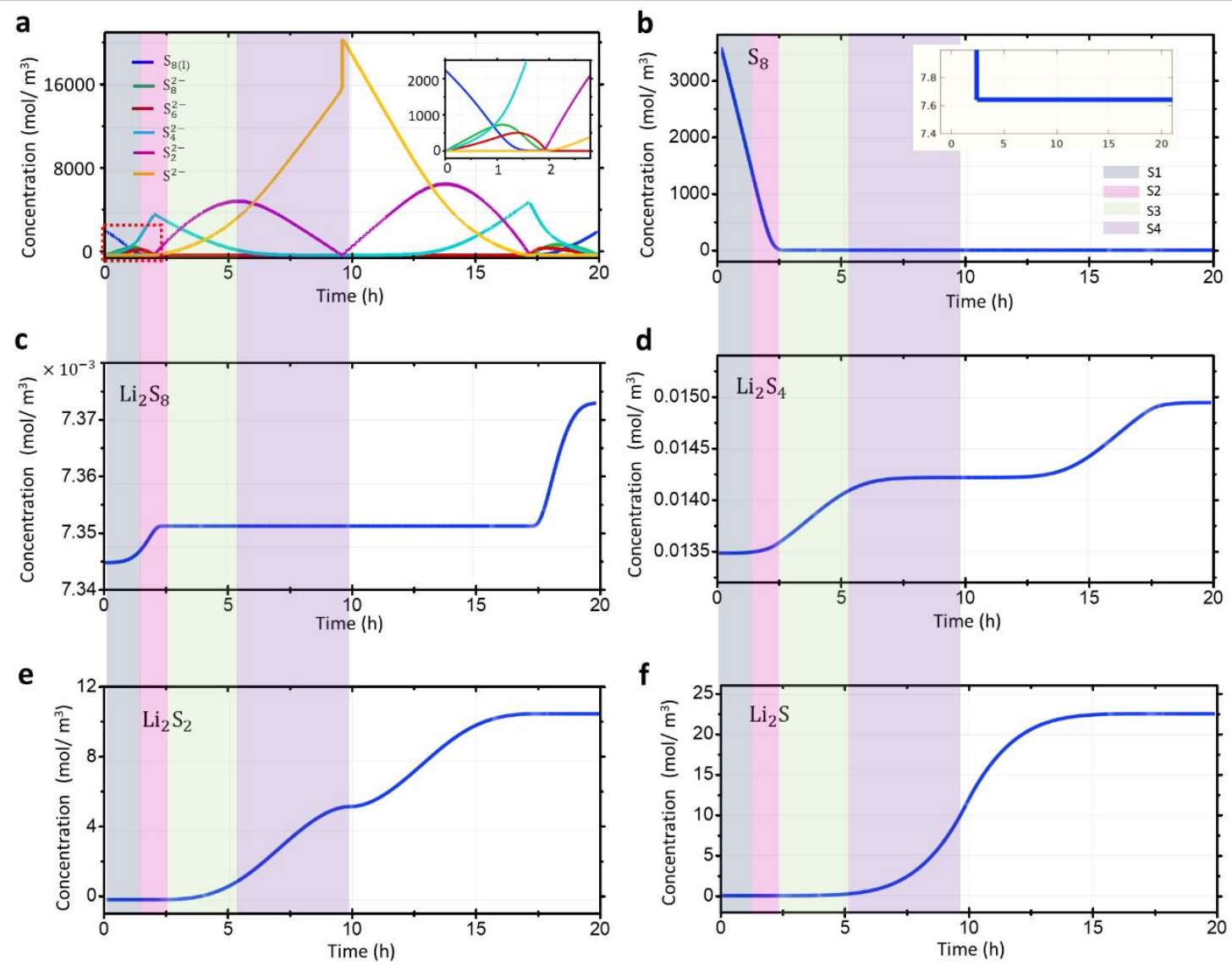

Figure S6. (a) Simulated concentration variations of PSs during one discharge-charge cycle. The same as Figure $1 \mathrm{~g}$ in the manuscript. (b-f) Simulated solid species $k\left(\mathrm{~S}_{8}(s), \mathrm{Li}_{2} \mathrm{~S}_{8}(s), \operatorname{Li}_{2} \mathrm{~S}_{4}(s), \mathrm{Li}_{2} \mathrm{~S}_{2}(s)\right.$, $\mathrm{Li}_{2} \mathrm{~S}(\mathrm{~s})$ ) evolution profiles during one discharge-charge cycle. The discharge profile was divided into four sections: S1-dominated by Reaction C1; S2-dominated by Reaction C2 and C3; S3dominated by Reaction C4; S4-dominated by Reaction C5. The inset of (b) shows zoom-in concentration of $S_{8}(s)$. 
a

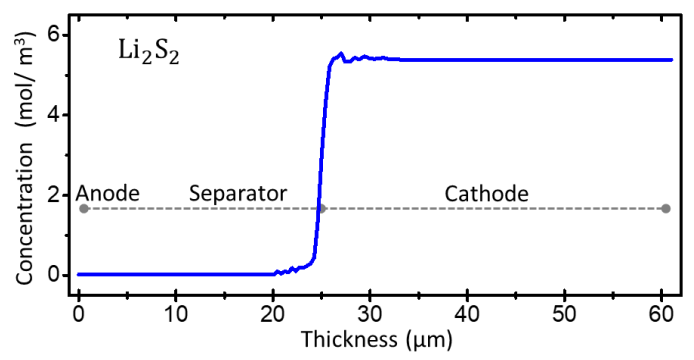

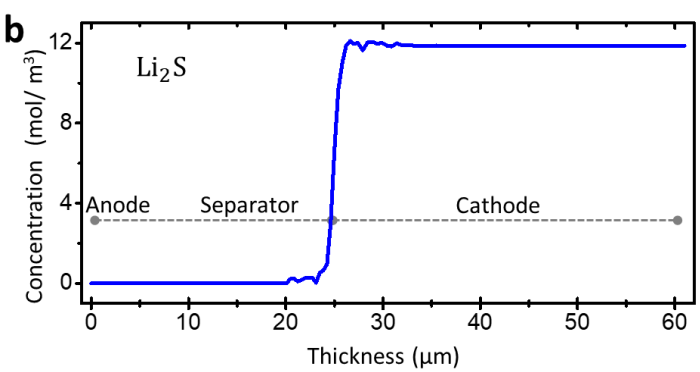

Figure S7. Spatial concentration distributions of $\mathrm{Li}_{2} \mathrm{~S}_{2}(\mathrm{~s})(\mathrm{a})$ and $\mathrm{Li}_{2} \mathrm{~S}(\mathrm{~s})(\mathrm{b})$ through the simulation domain at the end of first discharge. 


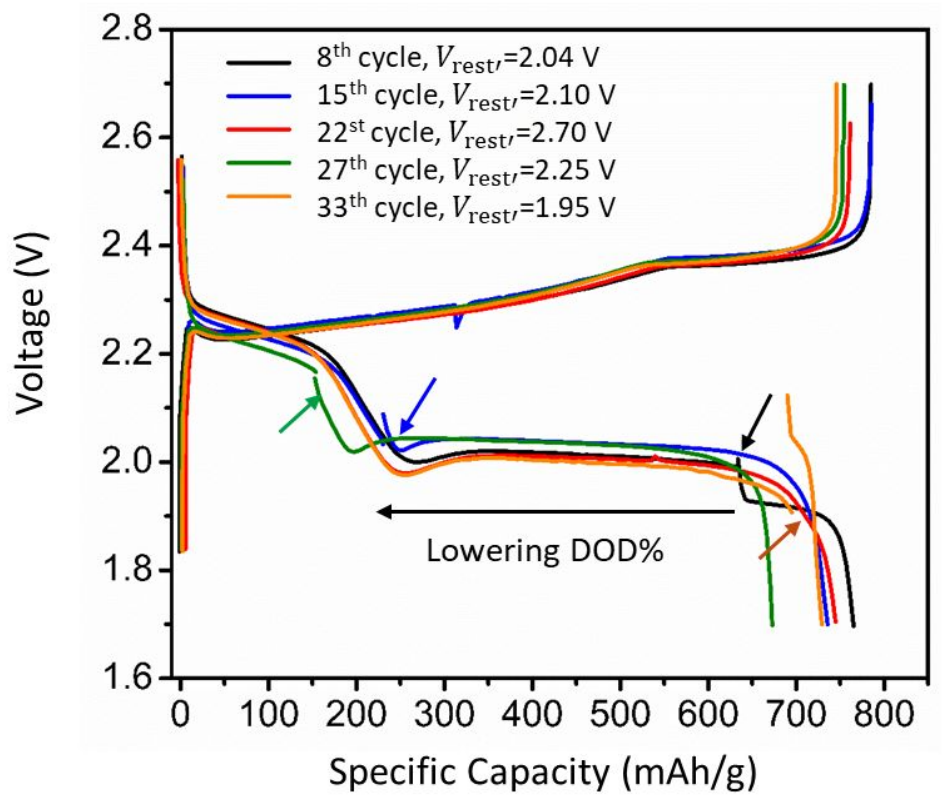

Figure S8. Experimental voltage profiles of the interrupted discharge plot at various resting voltages and the next immediate charge, (small coloured arrows show the point of resting). 


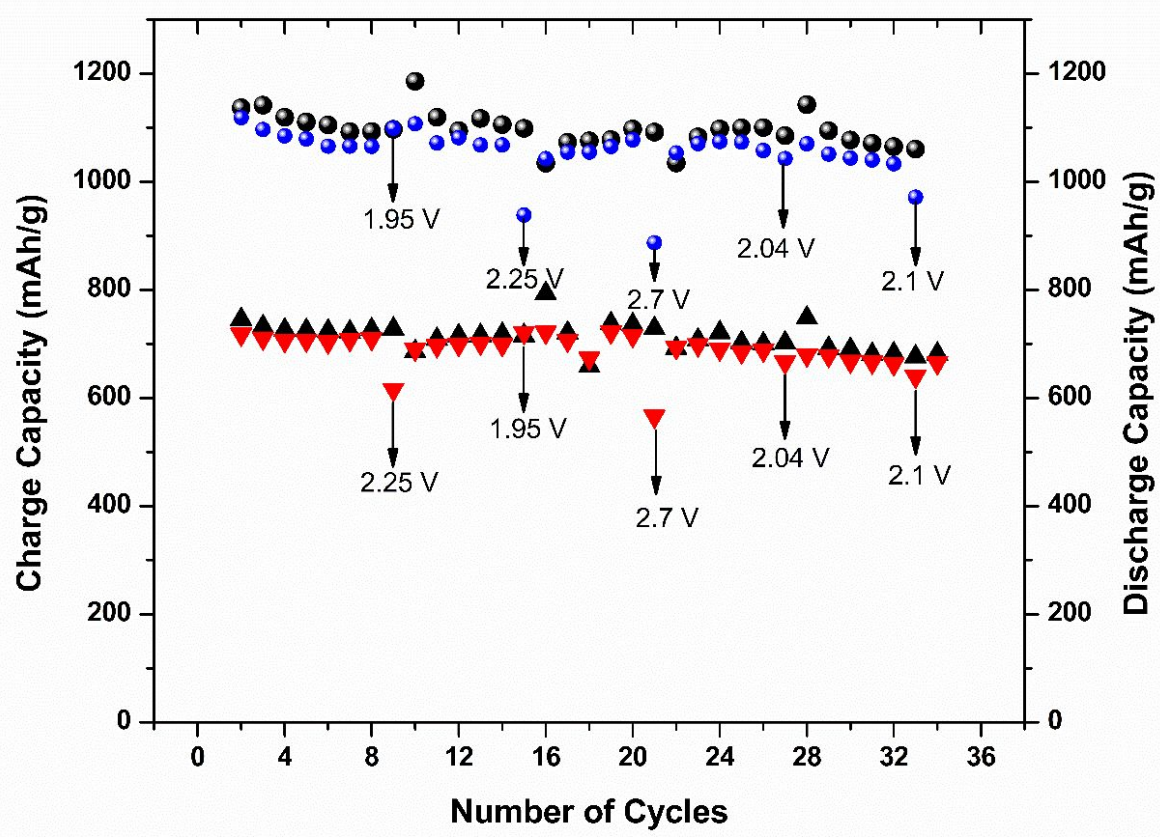

Figure 59. Variation of specific capacity as a function of cycle number over different selfdischarge period for different cycles.

Ex-situ XRD on the components of a cell (cathode, anode and separator) was carried out. Cells were disassembled after the 11th cycle when the cell was held for self-discharging at $22 \%$ DOD (2.1V) for $48 \mathrm{hr}$ and then completely discharged to $1.7 \mathrm{~V}$. The XRD samples were prepared inside the glove box, covered with Kapton film to slow the diffusion of air/moisture which would react with $\mathrm{Li}_{2} \mathrm{~S}$ and $\mathrm{Li}_{2} \mathrm{~S}_{2}$ to form products such as $\mathrm{H}_{2} \mathrm{~S}$. Figure R4a (i) \& (ii), compares the profiles of a control lithium disk and lithium anode after cycling. Both display a strong peak at $\sim 52.5^{\circ}$ corresponding to metallic lithium, ${ }^{6,7}$ while the control lithium exhibited an unknown peak at $27^{\circ}$ which might be some impurity as a result of reaction with air. Upon zooming in on the cycled lithium (Figure R4a (iii)), a small peak possibly corresponding to the (200) reflection of $\mathrm{Li}_{2} \mathrm{~S}$ (Figure R4a (iv)) matching with PDF \# 77-2145 is observed. ${ }^{8-13}$. However, higher order peaks could not be observed likely due to the poor signal to noise ratio. A sulfur cathode before and after cycling are compared in Figure R4b (i) \& (ii) along with the bare Kapton tape used to seal the samples. The broad background observed is due to the Kapton film (Figure R4b (iii)). ${ }^{14,15}$ The sulfur cathode before cycling (Figure R4b (i)) only shows a small peak at $26.5^{\circ}$ and corresponds to the unexfoliated graphitic domains of the commercial GNPs used. There are no peaks corresponding to crystalline sulfur (even though it is $\sim 50 \%$ by mass of the sample) suggesting that the sulfur is effectively amorphous in the composite. The profiles of the cycled cell look largely the same and do not show any significant $\mathrm{Li}_{2} \mathrm{~S}$ or $\mathrm{Li}_{2} \mathrm{~S}_{2}$ peaks despite the fact that the sulfur should be converted to $\mathrm{Li}_{2} \mathrm{~S}$ in the fully discharged state. Furthermore, the XRD pattern of the commercial PP separator used (Figure R4c (i)) and the PP separator of the cycled cell (Figure R4c (ii)) exhibits the characteristic diffraction peaks of PP at $14.05,17.1,18.75,21.45$ and $24^{\circ}{ }^{16-18}$ and there is no clear indication of $\mathrm{Li}_{2} \mathrm{~S}$ or $\mathrm{Li}_{2} \mathrm{~S}_{2}$ peaks. While these results only provide weak support for the formation of $\mathrm{Li}_{2} \mathrm{~S}$ on the Li metal surface, the absence of observable peaks does not mean they are not there. 
As discussed by others, these precipitates are expected to be amorphous or too small in size and concentration to be easily detected by a standard XRD. For example, Nelson et al ${ }^{13}$., Walus et al ${ }^{19}$., and Canas et $\mathrm{a}^{20}{ }^{20}$, reported In-situ X-ray diffraction (XRD) results of the operating cells and were only able to identify $\mathrm{Li}_{2} \mathrm{~S}$ as the discharge product, because it hydrolyzes easily in air, producing $\mathrm{H}_{2} \mathrm{~S}$ and $\mathrm{LiOH}$. Probable reasons why $\mathrm{Li}_{2} \mathrm{~S}$ has not been detected. 

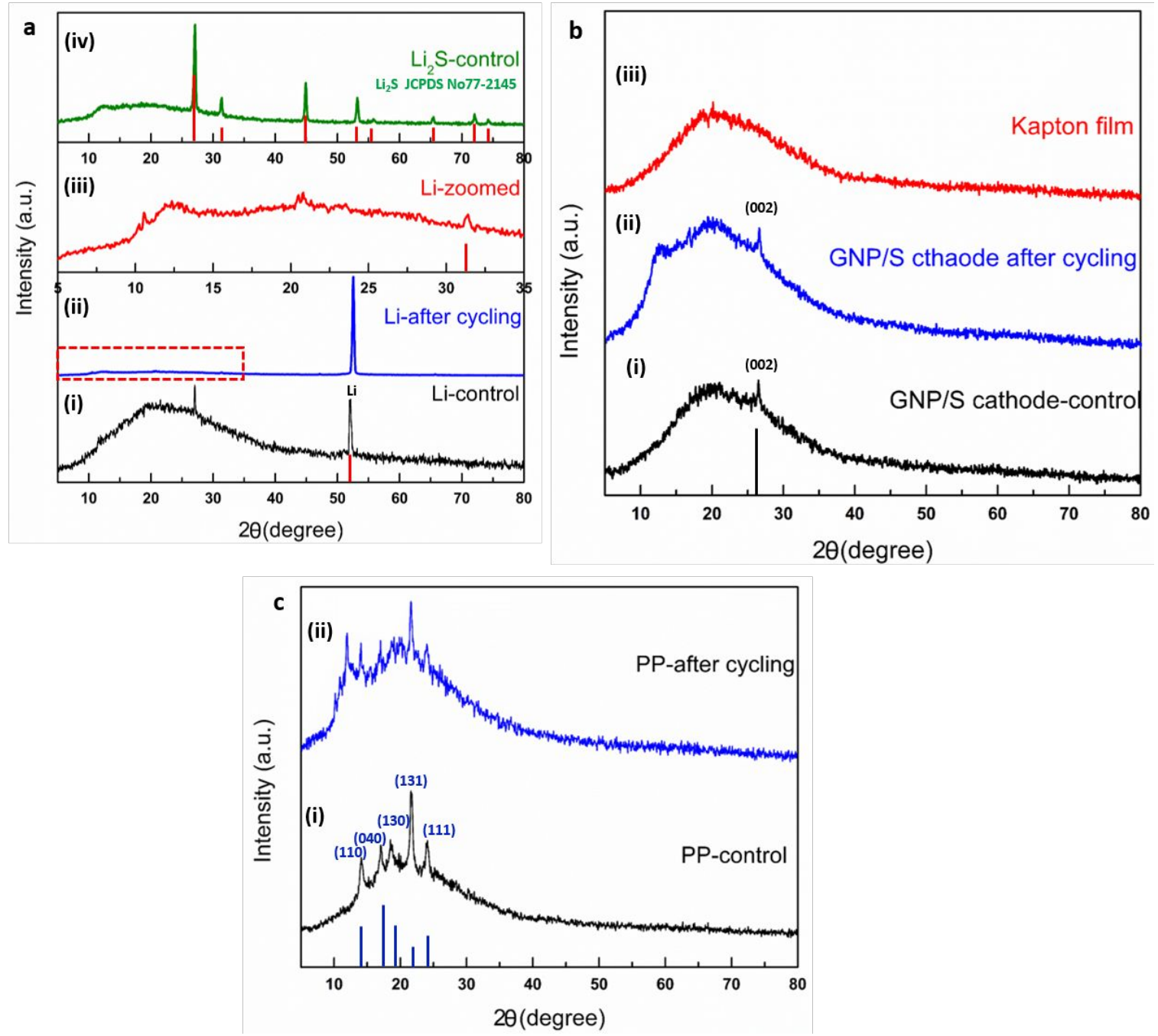

Figure S10. XRD patterns of various battery cell components: (a) (i) control lithium disk; (ii) lithium after cycling; (iii) zoomed in region from 5-350 of lithium after cycling; (iv) commercial $\mathrm{Li}_{2} \mathrm{~S}$ powder. (b) (i) GNP/sulfur cathode disk; (ii) GNP/sulfur cathode after cycling; (iii) Kapton film used to seal sample holder from ambient. (c) (i) commercial PP separator (ii)) PP separator after cycling. 


\section{References}

(1) Kumaresan, K.; Mikhaylik, Y.; White, R. E. A Mathematical Model for a Lithium-Sulfur Cell. J. Electrochem. Soc. 2008, 155, A576.

(2) Ghaznavi, M.; Chen, P. Sensitivity Analysis of a Mathematical Model of Lithium-Sulfur Cells Part I: Applied Discharge Current and Cathode Conductivity. J. Power Sources 2014, 257, 394-401.

(3) Wild, M.; O’Neill, L.; Zhang, T.; Purkayastha, R.; Minton, G.; Marinescu, M.; Offer, G. J. Lithium Sulfur Batteries, a Mechanistic Review. Energy Environ. Sci. 2015, 8, 3477-3494.

(4) Shen, C.; Xie, J.; Zhang, M.; Andrei, P.; Hendrickson, M.; Plichta, E. J.; Zheng, J. P. SelfDischarge Behavior of Lithium-Sulfur Batteries at Different Electrolyte/Sulfur Ratios. J. Electrochem. Soc. 2019, 166, A5287-A5294.

(5) Hofmann, A. F.; Fronczek, D. N.; Bessler, W. G. Mechanistic Modeling of Polysulfide Shuttle and Capacity Loss in Lithium-Sulfur Batteries. J. Power Sources 2014.

(6) Han, Y.; Duan, X.; Li, Y.; Huang, L.; Zhu, D.; Chen, Y. Effects of Sulfur Loading on the Corrosion Behaviors of Metal Lithium Anode in Lithium-Sulfur Batteries. Mater. Res. Bull. 2015, 68, 160-165.

(7) Giordani, V.; Uddin, J.; Bryantsev, V. S.; Chase, G. V; Addison, D. High Concentration Lithium Nitrate/Dimethylacetamide Electrolytes for Lithium/Oxygen Cells. J. Electrochem. Soc. 2016, 163, A2673.

(8) Li, F.; Wu, C.; Jiang, J.; Liu, H.-K.; Wang, J. A Conductive Polymer Derived N-Doped Carbon Nanofiber Supported Li2S Coating Layer for Li-S Batteries with High Mass Loading. J. Alloys Compd. 2020, 828, 154264.

(9) Hassoun, J.; Sun, Y.-K.; Scrosati, B. Rechargeable Lithium Sulfide Electrode for a Polymer Tin/Sulfur Lithium-lon Battery. J. Power Sources 2011, 196, 343-348.

(10) Paolella, A.; Zhu, W.; Marceau, H.; Kim, C.; Feng, Z.; Liu, D.; Gagnon, C.; Trottier, J.; Abdelbast, G.; Hovington, P. Transient Existence of Crystalline Lithium Disulfide Li2S2 in a Lithium-Sulfur Battery. J. Power Sources 2016, 325, 641-645.

(11) Carbone, L.; Verrelli, R.; Gobet, M.; Peng, J.; Devany, M.; Scrosati, B.; Greenbaum, S.; Hassoun, J. Insight on the Li $2 \mathrm{~S}$ Electrochemical Process in a Composite Configuration Electrode. New J. Chem. 2016, 40, 2935-2943.

(12) Lim, D.-H.; Agostini, M.; Nitze, F.; Manuel, J.; Ahn, J.-H.; Matic, A. Route to Sustainable Lithium-Sulfur Batteries with High Practical Capacity through a Fluorine Free Polysulfide Catholyte and Self-Standing Carbon Nanofiber Membranes. Sci. Rep. 2017, 7, 1-9.

(13) Nelson, J.; Misra, S.; Yang, Y.; Jackson, A.; Liu, Y.; Wang, H.; Dai, H.; Andrews, J. C.; Cui, Y.; Toney, M. F. In Operando X-Ray Diffraction and Transmission X-Ray Microscopy of Lithium Sulfur Batteries. J. Am. Chem. Soc. 2012, 134, 6337-6343.

(14) Shi, Y.; Wu, Y.; Sun, C.; Huo, M. Preparation and Characterization of Crystalline Titania Film on Polyimide Substrate by SILAR. Appl. Surf. Sci. 2014.

(15) Megusar, J. Low Temperature Fast-Neutron and Gamma Irradiation of Kapton ${ }^{\circledR}$ Polyimide Films. J. Nucl. Mater. 1997.

(16) Lin, Y.; Pitcheri, R.; Zhu, J.; Jiao, C.; Guo, Y.; Li, J.; Qiu, Y. Electrospun PVDF/PSSLi lonomer Films as a Functional Separator for Lithium-Sulfur Batteries. J. Alloys Compd. 2019, 785, 627-633. 
(17) Kang, G.; Li, L.; Wang, W.; Yu, D. Study of a Polyaniline/Polypropylene Collecting Electrode and Its Particle Removal Efficiency. RSC Adv. 2016, 6, 75038-75044.

(18) Niu, P.; Liu, B.; Wei, X.; Wang, X.; Yang, J. Study on Mechanical Properties and Thermal Stability of Polypropylene/Hemp Fiber Composites. J. Reinf. Plast. Compos. 2011, 30, 3644.

(19) Waluś, S.; Barchasz, C.; Colin, J. F.; Martin, J. F.; Elkaïm, E.; Leprêtre, J. C.; Alloin, F. New Insight into the Working Mechanism of Lithium-Sulfur Batteries: In Situ and Operando XRay Diffraction Characterization. Chem. Commun. 2013.

(20) Cañas, N. A.; Wolf, S.; Wagner, N.; Friedrich, K. A. In-Situ X-Ray Diffraction Studies of Lithium-Sulfur Batteries. J. Power Sources 2013. 